\title{
Glial Cell Line-Derived Neurotrophic Factor Reverses Alcohol-Induced Allostasis of the Mesolimbic Dopaminergic System: Implications for Alcohol Reward and Seeking
}

\author{
Segev Barak, ${ }^{\star}$ Sebastien Carnicella, ${ }^{\star}$ Quinn V. Yowell, and Dorit Ron \\ The Ernest Gallo Research Center, Department of Neurology, University of California, San Francisco, Emeryville, California 94608
}

\begin{abstract}
We previously showed that infusion of glial cell line-derived neurotrophic factor (GDNF) into the ventral tegmental area (VTA) rapidly reduces alcohol intake and relapse (Carnicella et al., 2008, 2009a), and increases dopamine (DA) levels in the nucleus accumbens (NAc) of alcohol-naive rats (Wang et al., 2010). Withdrawal from excessive alcohol intake is associated with a reduction in NAc DA levels, whereas drug-induced increases in NAc DA levels are associated with reward. We therefore tested whether GDNF in the VTA reverses alcohol withdrawal-associated DA deficiency and/or possesses rewarding properties. Rats were trained for 7 weeks to consume high levels of alcohol $(5.47 \pm 0.37 \mathrm{~g} / \mathrm{kg} / 24 \mathrm{~h})$ in intermittent access to $20 \%$ alcohol in a two-bottle choice procedure. Using in vivo microdialysis, we show that $24 \mathrm{~h}$ withdrawal from alcohol causes a substantial reduction in NAc DA overflow, which was reversed by intra-VTA GDNF infusion. Using conditioned place preference (CPP) paradigm, we observed that GDNF on its own does not induce CPP, suggesting that the growth factor is not rewarding. However, GDNF blocked acquisition and expression of alcohol-CPP. In addition, GDNF induced a downward shift in the dose-response curve for operant self-administration of alcohol, further suggesting that GDNF suppresses, rather than substitutes for, the reinforcing effects of alcohol. Our findings suggest that GDNF reduces alcohol-drinking behaviors by reversing an alcohol-induced allostatic DA deficiency in the mesolimbic system. In addition, as it lacks abuse liability, the study further highlights GDNF as a promising target for treatment of alcohol use/abuse disorders.
\end{abstract}

\section{Introduction}

Glial cell line-derived neurotrophic factor (GDNF) is a crucial growth factor for the development and maintenance of midbrain dopamine (DA) neurons (Lin et al., 1993; Airaksinen and Saarma, 2002; Bespalov and Saarma, 2007; Pascual et al., 2008), and activation of the GDNF pathway in the ventral tegmental area (VTA) has recently been suggested as a promising approach to treat addiction to drugs of abuse, including alcohol (Carnicella and Ron, 2009; Ghitza et al., 2010). Specifically for the latter, we showed that activation of the GDNF pathway in the VTA very rapidly reduces alcohol drinking and suppresses alcohol seeking during relapse in rats (Carnicella et al., 2008, 2009a). We further showed that the reduction of alcohol selfadministration by GDNF is mediated via the activation of extracellular signal-regulated kinases 1 and 2 (ERK1/2) (Carnicella et al., 2008).

\footnotetext{
Received April 7, 2011; revised May 16, 2011; accepted May 19, 2011.

Author contributions: S.B., S.C., and D.R. designed research; S.B., S.C., and Q.V.Y. performed research; S.B., S.C., Q.V.Y., and D.R. analyzed data; S.B., S.C., and D.R. wrote the paper.

*S.B. and S.C. contributed equally to this work.

This work was supported by NIH-NIAAA Grant R01 AA014366 (D.R.) and the State of California for Medical Research on Alcohol and Substance Abuse through the University of California, San Francisco (D.R.). We thank Dr. Patricia Janak for the critical review of this manuscript, and Dr. Howard Fields, Dr. Jennifer Mitchell, and Allison Coker for technical assistance.

Correspondence should be addressed to Dr. Dorit Ron, 5858 Horton Street, Suite 200, Emeryville, CA 94608. E-mail: dron@gallo.ucsf.edu.

S. Carnicella's present address: Grenoble Institute of Neuroscience, Inserm Unité 836, 38042 Grenoble, France. DOI:10.1523/JNEUROSCI.1750-11.2011

Copyright $\odot 2011$ the authors $\quad 0270-6474 / 11 / 319885-10 \$ 15.00 / 0$
}

More recently, we found that intra-VTA infusion of GDNF rapidly increases the spontaneous activity of DAergic neurons in this brain region, causing a subsequent elevation of extracellular DA levels in the nucleus accumbens (NAc), in an ERK1/2dependent manner (Wang et al., 2010). Conversely, withdrawal from chronic exposure to high levels of alcohol leads to a substantial reduction in the activity of DAergic VTA neurons that project to the NAc (Diana et al., 1993; Bailey et al., 2001; Shen, 2003; Shen et al., 2007), resulting in a reduction in DA levels in the NAc (Darden and Hunt, 1977; Rossetti et al., 1992; Diana et al., 1993; Weiss et al., 1996; Smith et al., 2008). This DA deficiency is suggested to play a key role in allostatic mechanisms that cause a progressive reduction in the hedonic/emotional set point, which leads to increased alcohol seeking and intake to restore the normal hedonic/emotional state (Ahmed and Koob, 1998; Koob and Le Moal, 2001; Koob, 2003). Thus, we hypothesized that GDNF attenuates alcohol seeking and consumption by reversing the deficiency in DA levels that occurs during alcohol withdrawal. However, like GDNF, virtually all drugs of abuse, including alcohol, acutely increase DA levels in the NAc of rodents (Di Chiara and Imperato, 1988; Gonzales et al., 2004; Hyman et al., 2006) and humans (Leyton, 2007), and this effect has been postulated to underlie some of the reinforcing properties of the drugs (McBride et al., 1999; Gonzales et al., 2004; Pierce and Kumaresan, 2006; Ikemoto, 2007). Therefore, we also tested whether intra-VTA infusion of GDNF is rewarding by itself, and whether GDNF alters the rewarding properties of alcohol. 
Table 1. Average alcohol intake and preference during the last week of the intermittent access to $20 \%$ alcohol two-bottle choice procedure

\begin{tabular}{lll}
\hline Experiment & $\begin{array}{l}\text { Alcohol intake } \\
(\mathrm{g} / \mathrm{kg} / 24 \mathrm{~h})\end{array}$ & $\begin{array}{l}\text { Alcohol } \\
\text { preference }(\%)\end{array}$ \\
\hline Microdialysis $(n=14)$ & $5.47 \pm 0.37$ & $0.53 \pm 0.07$ \\
CPP to alcohol-acquisition $(n=26)$ & $5.33 \pm 0.11$ & $0.55 \pm 0.02$ \\
CPP to alcohol- expression $(n=32)$ & $4.95 \pm 0.22$ & $0.50 \pm 0.03$ \\
Operant alcohol self-administration $(n=9)$ & $6.17 \pm 0.75$ & $0.55 \pm 0.07$ \\
\hline
\end{tabular}

\section{Materials and Methods}

Animals

Male Long-Evans rats (280-300 g at the beginning at the experiment) were obtained from Harlan. Rats were housed in individual cages under a $12 \mathrm{~h}$ light/dark cycle, with lights on at 7:00 A.M. and food and water available ad libitum. All animal procedures in this report were approved by the Gallo Center Institutional Animal Care and Use Committee and were conducted in agreement with the Guide for the Care and Use of Laboratory Animals (National Research Council, 1996).

\section{Intermittent access to $20 \%$ alcohol two-bottle choice drinking procedure}

High levels of voluntary alcohol consumption were obtained in an intermittent access to $20 \%$ alcohol two-bottle choice drinking procedure, which generates blood alcohol concentrations of $80.9 \pm 7.2 \mathrm{mg} \%$ (Carnicella et al., 2009a). Briefly, animals were given $24 \mathrm{~h}$ concurrent access to one bottle of $20 \%(\mathrm{v} / \mathrm{v})$ alcohol in tap water and one bottle of water on Monday, Wednesday, and Friday, with 24 or $48 \mathrm{~h}$ alcohol deprivation periods in between the alcohol-drinking sessions. The procedure was terminated after 21 alcohol-drinking sessions, when a stable baseline of alcohol consumption of $5-6 \mathrm{~g} / \mathrm{kg} / 24 \mathrm{~h}$ was achieved (Table 1).

\section{In vivo microdialysis}

Surgery. After achieving a stable baseline of alcohol consumption during training in a 7 week intermittent-access two-bottle choice drinking procedure as described above, rats were anesthetized with isoflurane (Baxter Health Care). Unilateral guide cannulae for microinjection (26G; Plastics One) were placed dorsal to the VTA as described below, and guide cannulae for the microdialysis probes (CMA/11; CMA/Microdialysis) were placed dorsal to the NAc (in mm relative to the bregma: $+1.5 \mathrm{AP},+1.1$ $\mathrm{ML},-6.5 \mathrm{DV})$. After the surgery, animals were allowed to recover for $1 \mathrm{~d}$ before being put back into the intermittent-access two-bottle choice regimen. Rats had three more alcohol access sessions before the microdialysis began (Table 1).

Microdialysis procedure. Microdialysis was performed as previously described (Zapata and Shippenberg, 2005; Wang et al., 2010) and began immediately after the third postsurgery session of $24 \mathrm{~h}$ alcohol access ("alcohol" group), or $24 \mathrm{~h}$ after this session was terminated [i.e., after $24 \mathrm{~h}$ of alcohol withdrawal ("wdrw" groups)]. An alcohol-naive control group ("water" group) was implanted with guide cannulae as described above. Probes ( $2 \mathrm{~mm}$ membrane length) were inserted into guide cannulae and connected to the dialysis system. Rats were housed in the microdialysis chamber with food and water, and the probes equilibrated over $1 \mathrm{~h}$ at a flow rate of $0.6 \mu \mathrm{l} / \mathrm{min}$ with aCSF (in mM: $149 \mathrm{NaCl}, 2.8 \mathrm{KCl}$, $1.2 \mathrm{MgCl}_{2}, 1.2 \mathrm{CaCl}_{2}$, and 5.4 D-glucose, pH 7.3 adjusted with $\mathrm{NaOH}$ ) before the beginning of the sample collection. Dialysis fractions were collected every $15 \mathrm{~min}$, frozen at $-80^{\circ} \mathrm{C}$, and analyzed for DA content within $48 \mathrm{~h}$ using HPLC electrochemical detection. After collection of four samples, the "wdrw" groups received an infusion of $1 \mu$ l of GDNF (10 $\mu \mathrm{g} / \mathrm{side}$; R\&D Systems) or PBS infusion as described below.

DA level determination. Dialysate DA levels were determined as previously described (Wang et al., 2010). Briefly, the chromatographic system used consisted of an ESA model 584 pump and ESA microtiter model 540 (ESA; Analytical), an ESA Coulochem III amperometric detector with a model 5011A dual-detector analytical cell (guard cell, $275 \mathrm{mV}$; E1, - 150 $\mathrm{mV}$; E2, $220 \mathrm{mV})$, and a microbore column $(50 \mathrm{~mm} \times 1.5 \mathrm{~mm} \times 3 \mu \mathrm{m}$; Shizeido). The mobile phase ( $150 \mathrm{~mm} \mathrm{NaH}_{2} \mathrm{PO}_{4}, 4.76 \mathrm{~mm}$ citric acid, 50 $\mu \mathrm{M}$ EDTA, 3 mм SDS, $8 \%$ methanol, 10\% acetonitrile, $\mathrm{pH} 5.6$ adjusted with $\mathrm{NaOH}$ ) was run at a flow rate of $0.2 \mathrm{ml} / \mathrm{min}$. DA in the dialysates was quantified by comparing DA peaks to external standards.

\section{Surgery and intra-VTA infusions}

Rats were anesthetized continuously with isoflurane (Baxter Health Care). Guide cannulae (26 ga; Plastics One) were aimed dorsal to the VTA (in mm relative to bregma: $-5.6 \mathrm{AP}, \pm 0.75 \mathrm{ML},-8.0 \mathrm{DV}$ ), according to Paxinos and Watson (1998). The coordinates were chosen according to previous studies (Carnicella et al., 2008, 2009c). After recovery and habituation to the microinjection procedure, GDNF (10 $\mu \mathrm{g} / \mu \mathrm{l} / \mathrm{side}$ ) or vehicle (PBS) were infused over 2 min to gently restrained rats via injection cannula ( 33 ga; Plastics One) extending $0.5 \mathrm{~mm}$ beyond the guide cannula tip. The dose of GDNF was chosen based on our previous studies, in which we tested a range of doses and determined that this specific dose produces (1) a robust suppression of alcohol intake in operant and nonoperant procedures and of relapse to alcohol drinking (Carnicella et al., 2008, 2009a), (2) an activation of the ERK1/2 pathway in the VTA in vivo (Carnicella et al., 2008), (3) an increase in the spontaneous firing of VTA DA neurons in vivo, and (4) an increase in DA levels in the NAc in alcohol-naive rats in vivo (Wang et al., 2010).

\section{Conditioned place preference apparatus and procedure}

Apparatus. Animals were trained in identical three-chamber conditioned place preference (CPP) boxes (MED Associates) consisting of a small gray middle chamber $(12 \times 21 \times 21 \mathrm{~cm})$ joined to two larger side chambers $(28 \times 21 \times 21 \mathrm{~cm})$ that differ in color, lighting, and floor texture. Total time spent in each chamber as well as horizontal locomotor activity was automatically recorded by infrared beam breaks.

Place conditioning to GDNF. After recovery from surgery for cannula implantation and habituation to the microinjections procedure, rats were allowed to explore the entire apparatus for $30 \mathrm{~min}$ for habituation, and to obtain the baseline measurements (day 1, preconditioning session). Animals that spent $>70 \%$ of the time in either one of the chambers during the preconditioning baseline session were excluded from the study. This allowed the use of an unbiased design in which the two sides of the chambers were equally preferred before conditioning as indicated by the group average (unbiased apparatus) and to pseudorandomly assign the compartment paired with alcohol (unbiased assignment procedure) (Tzschentke, 2007; Carnicella et al., 2009b). The next day, the conditioning training started with one conditioning trial per day during $6 \mathrm{~d}$ (days 2-7). GDNF (10 $\mu \mathrm{g} / \mu \mathrm{l} / \mathrm{side})$ or vehicle was infused into the VTA $10 \mathrm{~min}$ before confinement of the animals for $30 \mathrm{~min}$ in the paired side chamber (days 3, 5, and 7). All animals were infused with vehicle 10 min before confinement in the unpaired side chamber (days 2, 4, and 6). On day 8, animals were allowed to explore the entire apparatus for $30 \mathrm{~min}$ (postconditioning test session) as during habituation, and preference was scored by dividing the time spent in the paired compartment by the time spent in the unpaired compartment during this session (preference ratio) (Carnicella et al., 2009b; Velázquez-Sánchez et al., 2009; Gibb et al., 2011). Three conditioning sessions were chosen as three to four sessions are generally used to obtain robust CPP to rewarding substances, including drugs of abuse, in rodents (Cunningham et al., 2006; Tzschentke, 2007). Parameters for the GDNF infusion and the time of the conditioning session were chosen based on previous studies showing that intraVTA infusion of $10 \mu \mathrm{g} / \mu \mathrm{l} /$ side of GDNF induces a rapid (within $10 \mathrm{~min}$ ) increase in DA levels in the NAc that peaks 30-40 min after infusion (Wang et al., 2010) and is highly effective to reduce alcohol-drinking behaviors (Carnicella et al., 2008, 2009a).

Place conditioning to alcohol. Rats were first exposed to the intermittent access to $20 \%$ alcohol in a two-bottle choice drinking procedure for 7 weeks as described above. After establishing a baseline level of alcohol intake, the surgery for cannulae implantation was conducted. After recovery and habituation to the microinjections procedure, rats were allowed to freely explore the apparatus for $30 \mathrm{~min}$ (day 1) as described above. Animals that spent $>70 \%$ of the time in either one of the chambers during the preconditioning baseline session were excluded from the study (two to three rats per experiment).

Importantly, a history of excessive alcohol consumption did not significantly alter spontaneous locomotor activity, nor did it change the 
Table 2. Locomotor activity and time spent in the black chamber of alcohol-naive and alcohol-experienced animals in the preconditioning habituation stage of CPP

\begin{tabular}{llll}
\hline & Alcohol-naive & Alcohol-experienced & $t$ test \\
\hline $\begin{array}{c}\text { Locomotor activity } \\
\text { (beam breaks in 30 min) }\end{array}$ & $1925 \pm 69$ & $1883 \pm 56$ & $p>0.05$ \\
$\begin{array}{c}\text { Percentage of time spent } \\
\text { in the black chamber }\end{array}$ & $49.8 \pm 2.5$ & $54.1 \pm 1.6$ & $p>0.05$ \\
\hline
\end{tabular}

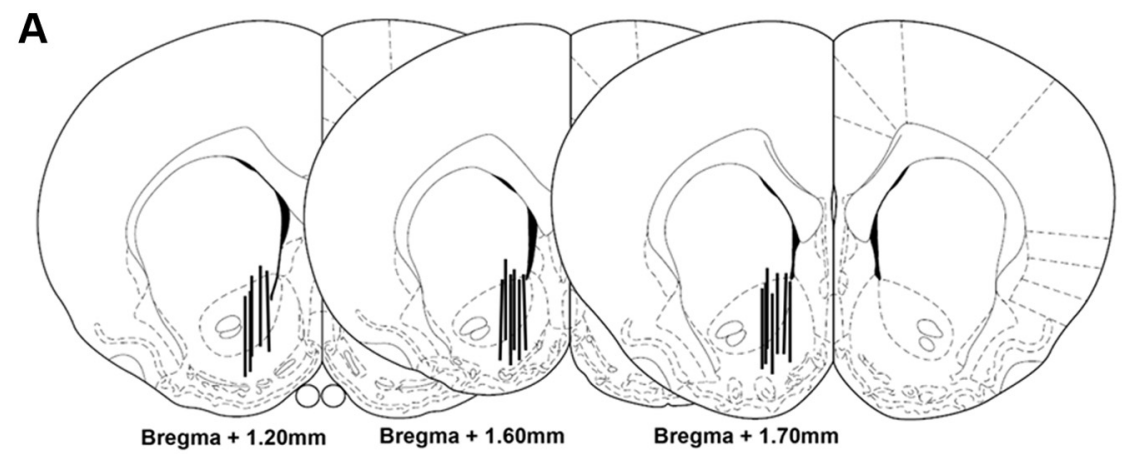

B

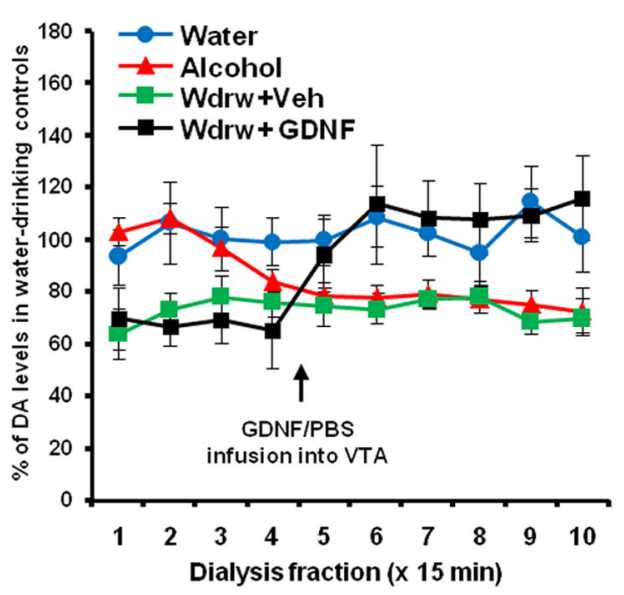

C

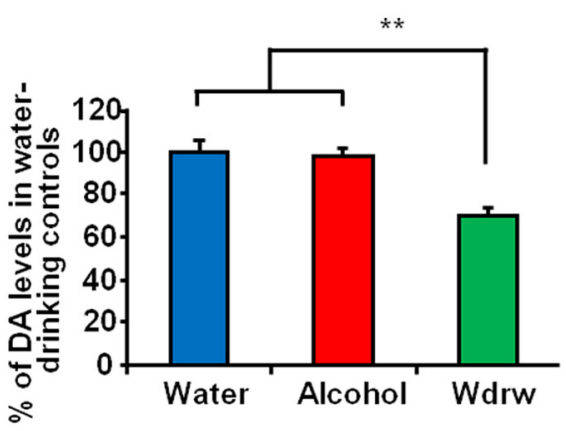

D

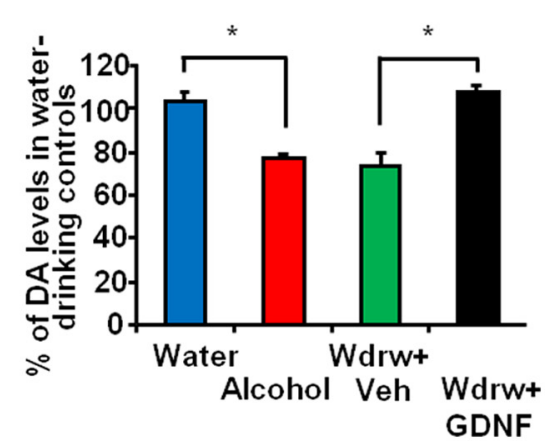

Figure 1. Intra-VTA infusion of GDNF reverses alcohol withdrawal-associated NAC DA deficiency. Rats were trained to achieve a stable level of alcohol intake using the intermittent access to $20 \%$ alcohol in two-bottle choice procedure. For the alcohol group (red), microdialysis was performed immediately after the last session of $24 \mathrm{~h}$ alcohol access, whereas for the withdrawal group (wdrw) (green and black), microdialysis was performed $24 \mathrm{~h}$ after the last drinking session was terminated. An alcohol-naive control group (water) (blue) was included as a control. Samples were collected every $15 \mathrm{~min}$. After collecting four samples, the wdrw group was infused with GDNF (10 $\mu \mathrm{g} / \mu \mathrm{l} / \mathrm{side}$; black) or vehicle (green) into the VTA and returned to the microdialysis chambers for an additional $90 \mathrm{~min}$. A, Schematic representation of the microdialysis probe placement in coronal sections (Paxinos and Watson, 1998). The locations of the dialysis membrane are represented by vertical bars. The numbers indicate the distance anterior to bregma (in millimeters). $\boldsymbol{B}-\boldsymbol{D}, N A c D A$ levels are presented as mean percentage ( \pm SEM) of the baseline of water controls. $\boldsymbol{B}$, DA levels in the NAc throughout 10 fractions of 15 min in the water, alcohol, wdrw + veh, and wdrw + GDNF groups. C, Average NAc DA levels during fractions $1-4$ in the water, alcohol, and wdrw groups. ${ }^{* *} p<0.01$. D, Average NAc DA levels during fractions $5-10$ (following intra-VTA GDNF or vehicle infusion to wdrw groups) in the water, alcohol, wdrw + veh, and wdrw + GDNF groups. ${ }^{*} p<0.05 . n=4-6$. time spent in the white and black chambers in the preconditioning habituation session (Table 2). Conditioning training started the next day with one conditioning trial per day during $4 \mathrm{~d}$ (days $2-5)$. Alcohol $(0.5$ imals were immediately confined for $7 \mathrm{~min}$ in the paired side chamber ays 3 and 5). All animals received an intraperitoneal administration of saline before the unpaired conditioning session (days 2 and 4 ). Short conditioning sessions are typically used to avoid association of the chamber with the aversive effects of alcohol that occur after this period of time, when brain or blood alcohol levels peak [e.g., $5 \mathrm{~min}$ in mice (Cunningham et al., 2006)]. In rats, as brain and blood alcohol levels peak between 5 and 10 min after an intraperitoneal administration (Lewis and June, 1990; Nurmi et al., 1994; Ginsburg et al., 2008), we choose a $7 \mathrm{~min}$ time point. The postconditioning test session (day 6) was conducted and analyzed as described above. GDNF (10 $\mu \mathrm{g} / \mu \mathrm{l} / \mathrm{side}$ ) or vehicle was infused into the VTA $10 \mathrm{~min}$ before the conditioning sessions or the test session depending on the experiment.

\section{Operant alcohol self-administration after history of high voluntary alcohol consumption}

The experiment began after rats achieved a stable baseline of alcohol consumption following 7 weeks training in the intermittent access to $20 \%$ alcohol two-bottle choice drinking procedure as described above. Rats were then trained to self-administer a $20 \%$ alcohol solution in the operant self-administration chambers (MED Associates). The operant self-administration training was conducted as previously described (Carnicella et al., 2008, 2009a), leading to a stable baseline of operant performance to obtain the delivery $0.1 \mathrm{ml}$ of a $20 \%$ alcohol solution under a fixed ratio 3 (FR3) schedule, during 30 min sessions, $5 \mathrm{~d}$ per week. After 1 month of training, surgery to implant cannulae was conducted and alcohol self-administration resumed after $3 \mathrm{~d}$ of recovery, until presurgery baseline of alcohol self-administration was established. Then, different concentrations of alcohol were presented in the following ascending order: $2.5,10,20$, and $40 \%$. We recently showed that this procedure leads to a typical inverted U-shaped dose-response curve, indicative of a tight autoregulation of alcohol intake by the rats (i.e., consumption volumes become lower as alcohol concentration increases, to maintain steady alcohol intake level) (Carnicella et al., 2011). Each alcohol concentration was presented $5 \mathrm{~d}$ a week for 2 weeks, and GDNF ( $10 \mu \mathrm{g} / \mu \mathrm{l} / \mathrm{side})$ or vehicle was infused into the VTA $10 \mathrm{~min}$ before the third session (i.e., on Wednesday) of each week in a counterbalanced order.

\section{Histology}

Locations of cannulae and microdialysis probes were verified in $60 \mu \mathrm{m}$ coronal sections of paraformaldehyde-fixed tissue stained with thionin. Only data from subjects with cannulae located in the region of interest were included in the analysis. Microdialysis probe placements are represented in Figure $1 \mathrm{~A}$ and cannulae were localized within a posterior area of the VTA, as defined by Carnicella et al. (2008). 
Statistical analysis

Data were analyzed using a two-way ANOVA with repeated measures (full or mixed withinsubject design), followed by Student-NewmanKeuls test or the method of contrasts (Keppel, 1991; Carnicella et al., 2009b) where indicated.

\section{Results}

Reduction in basal NAc DA levels, induced by withdrawal from long-term excessive alcohol consumption, is reversed by intra-VTA infusion of GDNF

Withdrawal from chronic exposure to alcohol (using oral gavage or selfadministration) has been reported to result in a substantial reduction in DA levels in the NAc (Darden and Hunt, 1977; Rossetti et al., 1992; Diana et al., 1993; Weiss et al., 1996; Smith et al., 2008). We recently demonstrated that intra-VTA GDNF infusion rapidly increases NAc DA overflow in alcohol-naive rats (Wang et al., 2010). Thus, we determined whether withdrawalassociated DA deficiency could be reversed by GDNF in the VTA. First, we tested whether basal NAc DA levels are reduced during acute alcohol withdrawal following intermittent access to $20 \%$ alcohol in twobottle choice procedure. A $24 \mathrm{~h}$ withdrawal period resulted in a significant reduction in DA levels in the NAc of rats with a history of prolonged excessive ( $\sim 5.5 \mathrm{~g} / \mathrm{kg} / 24 \mathrm{~h})$ alcohol intake, compared with waterdrinking controls (Fig. $1 B-D$, water vs wdrw). Interestingly, the DA levels in the NAc of rats that underwent the same alcohol consumption procedure, but were tested immediately after the end of the session, were initially similar to those of water-drinking controls (Fig. $1 B, C$, water vs alcohol), but 45-60 min later the DA levels lapsed back to the level of the withdrawal animals (Fig. $1 B, D$, water vs alcohol). These findings suggest that, during and shortly after an alcoholdrinking session, animals exhibit normal DA levels in the NAc, but subsequent, withdrawal from alcohol causes a notable DA deficiency. Importantly, as shown in Figure $1, B$ and $D$, infusion of GDNF into the VTA after $24 \mathrm{~h}$ of withdrawal from alcohol increased DA to the levels of the water control group. A two-way mixed-design ANOVA (group by fractions) yielded a significant interaction $\left(F_{(27,126)}=5.26 ; p<0.0001\right)$ (Fig. $\left.1 B\right)$, but no main effects of group $\left(F_{(3,14)}=2.52 ; p=0.10\right)$ or fractions $\left(F_{(9,126)}=1.34 ; p=0.22\right)$. Post $h o c$ analysis using the method of contrasts showed a significant difference in fractions 1-4 between the wdrw and both the alcohol and the water groups (values of $t>3.23$; values of $p<0.01$ ) (Fig. 1C), and in fractions $5-10$ between the water and alcohol groups $(t=$ 2.23; $p<0.05$ ) (Fig. 1D) and between the wdrw-GDNF and wdrwvehicle groups $(t=2.67 ; p<0.02)$ (Fig. $1 D)$. These results suggest that intra-VTA GDNF infusion reverses DA deficiency associated with alcohol withdrawal.

Intra-VTA infusion of GDNF does not induce CPP and does not alter locomotor activity

The rewarding properties of drugs of abuse are associated with elevation of DA levels in the NAc (Di Chiara and Imperato,
1988; Gonzales et al., 2004; Leyton, 2007). Intra-VTA infusion of GDNF also elevates NAc DA levels (Wang et al., 2010) and, in addition, reduces alcohol consumption (Carnicella et al., 2008, 2009a). Thus, we set out to test whether GDNF in the VTA possesses intrinsic rewarding/reinforcing effects on its own and as a consequence can potentially substitute for alcohol. Drug-induced CPP is a widely accepted measurement of the rewarding/reinforcing property of the drug (Cunningham et al., 2006; Tzschentke, 2007), and therefore, we first examined whether intra-VTA infusion of GDNF induces CPP. The design and schedule of the experiment are summarized in Figure $2 A$. As shown in Figure $2 B$, rats did not exhibit preference (or aversion) for the chamber paired with GDNF (no effects of treatment: $F_{(1,12)}=0.01, p=0.92$; or conditioning: $F_{(1,12)}=0.01, p=0.94$; and no significant interaction: $F_{(1,12)}<0.01$, $p=0.95)$.

An increase in NAc DA levels induced by alcohol and psychostimulants is associated with an acute increase in locomotor activity (Meyer et al., 2009). We therefore tested whether locomotor activity during the conditioning sessions would be affected by GDNF. We found that intra-VTA infusion of GDNF did not alter locomotor activity assessed during the entire CPP conditioning sessions (Fig. $2 C$ ) (no effect of treatment: $F_{(1,26)}=0.42$, $p=0.53$; or session: $F_{(2,26)}=0.48, p=0.62$; and no interaction: $F_{(2,26)}=0.98, p=0.39$ ), or by blocks of $5 \mathrm{~min}$ (Fig. 2D) (signif- 
A
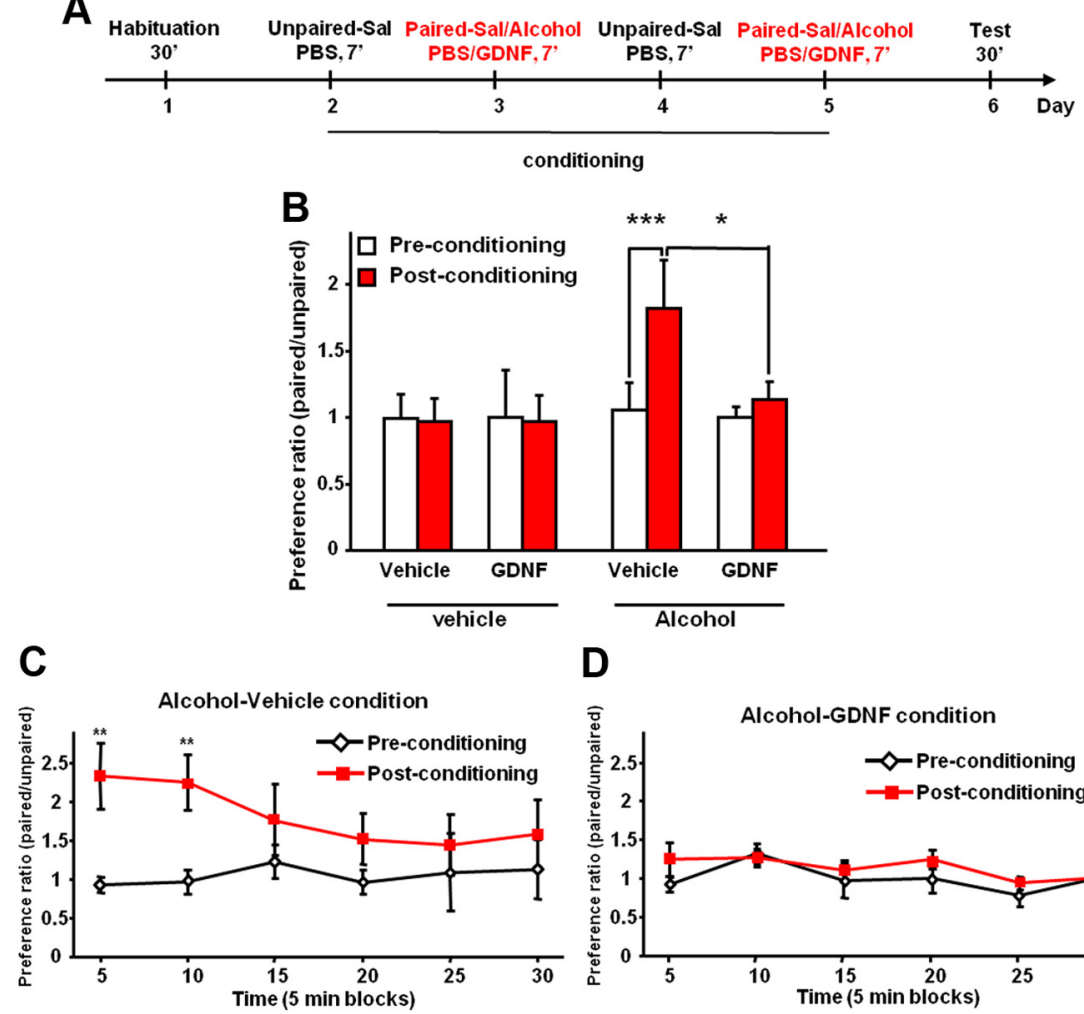

D

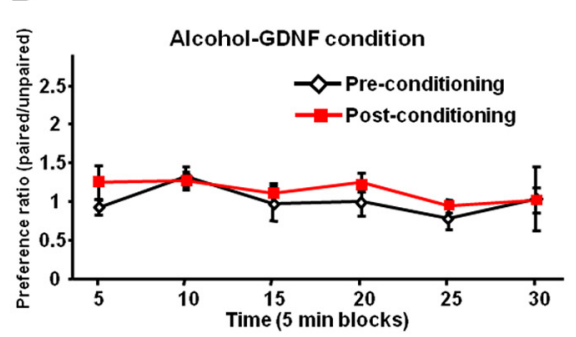

Figure 3. Intra-VTA infusion of GDNF inhibits acquisition of CPP to alcohol. $A$, Design and schedule of place conditioning experiment testing the effects of GDNF on acquisition of alcohol-CPP: alcohol ( $0.5 \mathrm{~g} / \mathrm{kg}, 15 \% \mathrm{v} / \mathrm{v}$ ) or saline (Sal) was administered intraperitoneally immediately before the $7 \mathrm{~min}$ conditioning paired sessions. Saline was administered before the conditioning unpaired sessions. Rats of the GDNF condition were infused into the VTA with GDNF ( $10 \mu \mathrm{g} / \mu \mathrm{l} / \mathrm{side}$ ) and vehicle (PBS) $10 \mathrm{~min}$ before the conditioning paired and unpaired sessions, respectively. Rats of the vehicle condition received vehicle only. $\boldsymbol{B}$, Place preference for alcohol expressed as the ratio \pm SEM of the time spent in the alcohol-paired and unpaired compartment during the entire session. $\boldsymbol{C}, \boldsymbol{D}$, Place preference to alcohol expressed as the ratio \pm SEM of the time spent in the alcohol-paired and unpaired compartment by blocks of $5 \mathrm{~min}$ for the alcohol-vehicle ( $\boldsymbol{C}$ ) or the alcohol-GDNF (D) conditions. $n=6-7 .{ }^{*} p<0.05$; ${ }^{* *} p<0.01$; ${ }^{* * *} p<0.001$

icant effect of time: values of $F_{(5,60)}>49.66$, values of $p<0.001$; but no effect of treatment: values of $F_{(1,60)}<1.36$, values of $p>$ 0.27 ; and no interaction: values of $F_{(5,60)}<1.29$, values of $p>$ $0.28)$. Together, these results suggest that GDNF in the VTA is not rewarding, and that unlike psychostimulants or alcohol, the growth factor does not increase locomotor activity.

\section{Intra-VTA infusion of GDNF inhibits both acquisition and expression of CPP to alcohol}

Acquisition of drug/alcohol-induced CPP is considered to be a measurement of the rewarding properties of the drug/alcohol (Cunningham et al., 2006; Tzschentke, 2007). If GDNF substitutes for the rewarding effects of alcohol, then infusion of the growth factor during the acquisition of alcohol-CPP will not affect, or even enhance, alcohol-CPP because the animals will still show preference for the alcohol-paired chamber. Thus, we investigated whether GDNF affects the acquisition of alcohol place preference. Rats were first subjected to the same alcohol consumption paradigm as in the experiments used to measure the level of DA [ 7 weeks of intermittent access to 20\% alcohol (Carnicella et al., 2009a)] before the initiation of the CPP procedure. The design and schedule of the experiment testing the effects of GDNF on acquisition of alcohol-CPP are summarized in Figure $3 A$. As shown in Figure $3 B$, rats that received vehicle during the conditioning period exhibited $\mathrm{CPP}$, whereas rats that were treated with GDNF during the acquisition of CPP did not exhibit CPP (no effect of treatment: $F_{(3,21)}=1.16, p=0.35$; but a significant effect of conditioning: $F_{(1,21)}=$ 4.77, $p<0.05$; and a significant interaction: $\left.F_{(3,21)}=4.17, p<0.02\right)$. Consistently, a marked preference for the alcohol-paired side was observed during the test session for the alcohol-vehicle condition (Fig. 3C) (no effect of time: $F_{(5,30)}=1.34, p=0.28$; significant effect of conditioning: $F_{(1,30)}=8.10, p<0.05$; and significant interaction: $F_{(5,30)}=2.54$, $p<0.05$ ), but not for the alcohol-GDNF condition (Fig. 3D) (no effects of time: $F_{(5,30)}=1.20, p=0.34$; or conditioning: $F_{(1,30)}=1.62, p=0.26$; and no interaction: $\left.F_{(5,30)}=0.52, p=0.76\right)$. Similarly to the results shown in Figure $2 B$, GDNF on its own did not induce place preference or aversion (Fig. 3B), suggesting that GDNF is not reinforcing in either alcohol-naive or alcohol-experienced animals. In addition, locomotor activity was not altered by the intra-VTA infusion of GDNF during conditioning (no effects of treatment: $F_{(3,21)}=1.02, p=0.39$; or session: $F_{(1,21)}$ $=1.37, p=0.54$; and no interaction: $\left.F_{(3,21)}=1.78, p=0.28\right)($ data not shown), suggesting an absence of pharmacological interaction between GDNF and alcohol.

Expression of drug/alcohol-induced CPP is considered to be a measurement of drug/alcohol seeking (Tzschentke, 2007; Gremel and Cunningham, 2009). Next, we determined whether GDNF in the VTA affects the expression of CPP to alcohol. Rats underwent a period of voluntary consumption of alcohol as above, and the design and schedule of the experiment testing the effects of GDNF on expression of alcohol-CPP are summarized in Figure $4 A$. As shown in Figure $4 B$, rats that received intra-VTA infusion of GDNF 10 min before the test session did not express preference for the alcohol-paired chamber compared with vehicle-treated group. A two-way ANOVA found no main effects of treatment $\left(F_{(3,28)}=0.95 ; p=\right.$ $0.42)$ or conditioning $\left(F_{(1,28)}=1.83 ; p=0.19\right)$, and a marginally significant interaction $\left(F_{(3,28)}=2.78 ; p=0.06\right)$. Post hoc analyses using the method of contrasts found a significant difference between preconditioning and postconditioning for the alcohol-vehicle group $\left(t_{(8)}=2.36 ; p<0.05\right)$, but not for other comparisons (values of $p>0.55$ ). A marked preference for the alcohol-paired side was also observed during the first $15 \mathrm{~min}$ of the test session for the alcohol-vehicle condition (Fig. 4C) (significant effects of time: $F_{(5,40)}=3.43, p<0.01$; and conditioning: $F_{(1,40)}=5.43, p<0.05$; but no interaction: $F_{(5,40)}=$ $1.34, p=0.27$ ), but not for the alcohol-GDNF condition (Fig. $4 D$ ) (no effects of time: $F_{(5,40)}=1.13, p=0.36$; or conditioning: $F_{(1,40)}=1.01, p=0.94$; and no interaction: $F_{(5,40)}=1.03$, $p=0.41)$. Together, these data suggest that intra-VTA infusion of GDNF induces a robust decrease in both the rewarding effects of alcohol and alcohol seeking, in alcohol-experienced rats. 
Intra-VTA infusion of GDNF produces a downward shift in the dose-response curve for alcohol

The fact that activation of the GDNF pathway in the VTA rapidly increases extracellular DA levels in the NAc (Wang et al., 2010) suggests that the growth factor may substitute for, or potentiate the, reinforcing effects of alcohol. However, the CPP findings described above indicate that GDNF acts as an inhibitor of alcoholinduced reward and alcohol seeking. To confirm the latter possibility, we tested whether GDNF acts to suppress the motivation to seek and consume alcohol by determining whether intra-VTA infusion of GDNF can shift the dose-response curve for alcohol self-administration downward.

Specifically, varying the concentrations of drugs such as psychostimulants and alcohol during an operant selfadministration procedure results in a typical inverted U-shaped dose-response curve (Ahmed and Koob, 1998; Lynch and Carroll, 2001; Carnicella et al., 2011) (Fig. $5 A$, model). The descending limb of this curve is indicative of a progressive decrease in responding as the dose increases to achieve, or maintain, a relatively constant level of drug intake (Koob, 1996; Ahmed and Koob, 1998; Lynch and Carroll, 2001; Carnicella et al., 2011). Interestingly, prolonged exposure to drugs of abuse including alcohol leads to an upward shift of the dose-response curve, and particularly of the descending limb, so that animals self-administer higher volumes of the drug across concentrations, reflecting an increased motivation to seek and consume the drug (Fig. 5C) (Ahmed and Koob, 1998; Graham et al., 2007; Simms et al., 2010; Carnicella et al., 2011). A substitution for, or a potentiation of, the reinforcing effect of alcohol would be expected to shift the dose-response function to the left (Fig. 5D), while a decrease in seeking and reinforcing properties of alcohol would be expected to produce a downward and/or a rightward shift (Fig. 5E) (Mello and Negus, 1996; Carnicella et al., 2011). We therefore took advantage of this procedure and tested whether and how infusion of GDNF into the VTA alters the dose-response curve of alcohol self-administration. We found that activation of the GDNF pathway in the VTA reduces operant responding for all concentrations of alcohol except the lowest $(2.5 \%)$, producing a downward shift in the alcohol dose-response curve (Fig. $5 F$ ) (main effects of alcohol concentration: $F_{(3,24)}=20.51, p<0.001$; and treatment: $F_{(1,24)}=48.58, p<$ 0.001 ; and a significant interaction: $\left.F_{(3,24)}=15.35, p<0.001\right)$. As a consequence of the reduced operant responding, alcohol intake was reduced at all relevant concentrations of alcohol (Fig. 5G) (main effects of alcohol concentration: $F_{(3,24)}=58.80, p<0.001$; and treatment: $F_{(1,24)}=35.10, p<0.001$; and a significant interaction: $\left.F_{(3,24)}=11.72, p<0.001\right)$. Together, our results suggest that activation of the GDNF signaling pathway in the VTA leads to a reduction in the motivation of rats to seek and consume alcohol, rather than to a substitution for the rewarding effects of alcohol.

\section{Discussion}

Here, we show that GDNF rapidly reverses the deficits in NAc DA levels during alcohol withdrawal, suggesting that activation of the GDNF pathway within the VTA antagonizes some of the allostatic neurochemical aberrations induced by prolonged excessive alcohol consumption. We show that intra-VTA infusion of GDNF inhibits alcohol reward and seeking, and produces a downward shift in the dose-response curve for operant alcohol self-administration. Furthermore, we report that, unlike alcohol, GDNF in the VTA is not rewarding on its own and does not alter locomotor activity. Together, our findings suggest that GDNF reduces alcohol seeking and intake by reversing allostatic changes within the mesolimbic DA system associated with long-term excessive alcohol consumption and withdrawal (Fig. 6, model).

\section{Intra-VTA infusion of GDNF reverses alcohol-induced allostatic aberration of the DA mesolimbic system}

Intermittent access to $20 \%$ alcohol in a two-bottle choice procedure leads to an escalation of alcohol intake (Wise, 1973; Carnicella et al., 2008, 2009a; Simms et al., 2008). We show that the repeated cycles of excessive drinking followed by short withdrawal periods cause a reduction in NAc DA levels during withdrawal. Specifically, following the termination of a drinking session, DA levels in the NAc rapidly decrease below the levels of alcohol-naive rats and remain lower for at least for $24 \mathrm{~h}$. Our findings are consistent with previous studies showing that short withdrawal periods from chronic exposure to high levels of alco- 

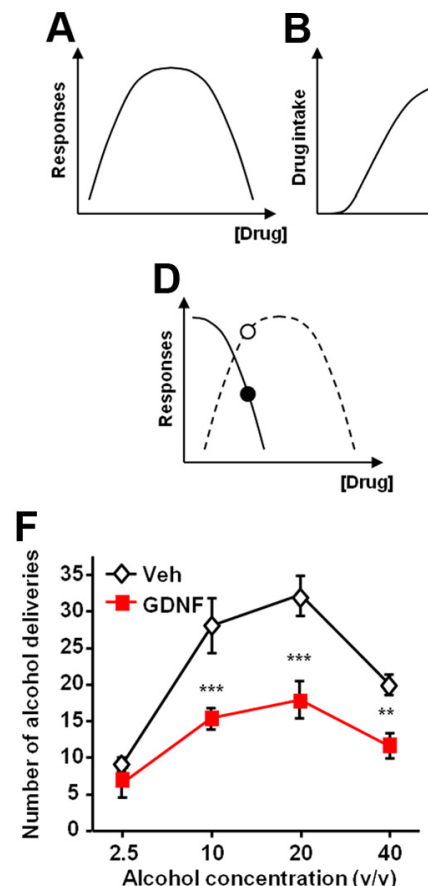

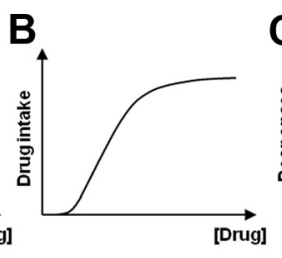

$\mathrm{E}$

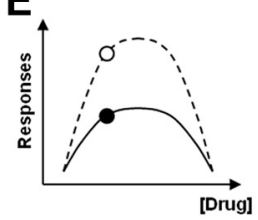

G

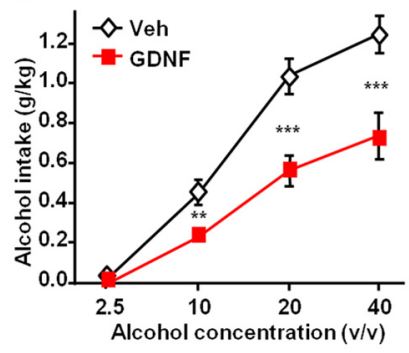

Figure 5. Intra-VTA infusion of GDNF produces a downward shift in the dose-response curve for alcohol. $\boldsymbol{A}-\boldsymbol{E}$, An illustrative theoretical dose-response curve for drug self-administration and its modulation by pharmacological agents. $\boldsymbol{A}, \boldsymbol{B}$, Number of operant responses $(\boldsymbol{A})$ and the resulting drug intake $(\boldsymbol{B})$ as a function of the dose of the presented drug. $\boldsymbol{C}-\boldsymbol{E}$, Pharmacological agents (potential therapeutics) can reduce self-administration at a relevant reinforcing dose of the drug of abuse (represented by the open and solid circle for the vehicle and treatment condition, respectively) by shifting the dose-response curve to the right ("antagonist" effect) ( $\mathbf{C}$, or to the left ("agonist" effect, that substitutes for the rewarding effects of the drug) $(\boldsymbol{D})$, or by inducing a downward shift (direct inhibition of the reinforcing effect of the drug) $(\boldsymbol{E})$. $\boldsymbol{F}, \mathbf{G}, \mathrm{GDNF}(10 \mu \mathrm{g} / \mu \mathrm{l} / \mathrm{side})$ or vehicle was infused into the VTA 10 min before 30 min operant oral alcohol self-administration sessions of $2.5,10,20$, and $40 \%$ alcohol. $\boldsymbol{F}$, Mean \pm SEM of the number of alcohol deliveries. $\boldsymbol{G}$, Mean \pm SEM of the alcohol intake (grams/kilogram). $n=9$. ${ }^{* *} p<0.01 ;{ }^{* * *} p<0.001$.
DA levels in the NAc are similar to those of water-drinking controls, suggesting that alcohol consumption reverses withdrawalassociated DA deficiency in the NAc, in line with previous reports (Weiss et al., 1996). These findings suggest that rats increase their alcohol consumption to reverse/counter the deficiency in DA.

Our findings also imply that, following a prolonged excessive consumption of alcohol, there is a shift to a new, lower allostatic set point of DA levels, providing support to the allostasis hypothesis of addiction (Koob and Le Moal, 1997, 2001; Koob, 2003). Specifically, Koob and Le Moal (2001) proposed that gradual downregulation of DA release in the NAc in response to longterm excessive drug intake is one of the mechanisms underlying the allostatic reduction in mood/hedonic levels associated with prolonged abuse of drugs/alcohol. This, in turn, leads to higher drug consumption to raise DA levels and hedonic mood (Koob and Le Moal, 2001), and indeed, we observed that alcohol consumption elevated NAc DA levels. Thus, DA deficiency is likely to play a crucial role in the development and maintenance of excessive alcohol consumption, as animals may seek to reverse the negative hedonic state associated with DA deficiency during withdrawal by consuming more alcohol to restore DA levels (Fig. 6 , model).

Importantly, we show here that infusion of GDNF into the VTA reverses the DA deficiency in the NAc associated with withdrawal after prolonged excessive drinking, namely, GDNF normalizes DA levels in the NAc. This possibility is in line with our recent findings that activation of the GDNF/ERK1/2 pathway in the VTA results in increased spontaneous activity of VTA DA neurons and in DA release in the NAc (Wang et al., 2010). Therefore, it is likely that GDNF attenuates alcohol-drinking behaviors (Carnicella et al., 2008, 2009a) by reversing the withdrawalassociated allostatic DA deficiency in the NAc. Specifically, normalization of NAc DA levels by GDNF during withdrawal decreases the motivation to seek and consume alcohol to elevate DA levels and to normalize the hedonic state (Fig. 6, model).

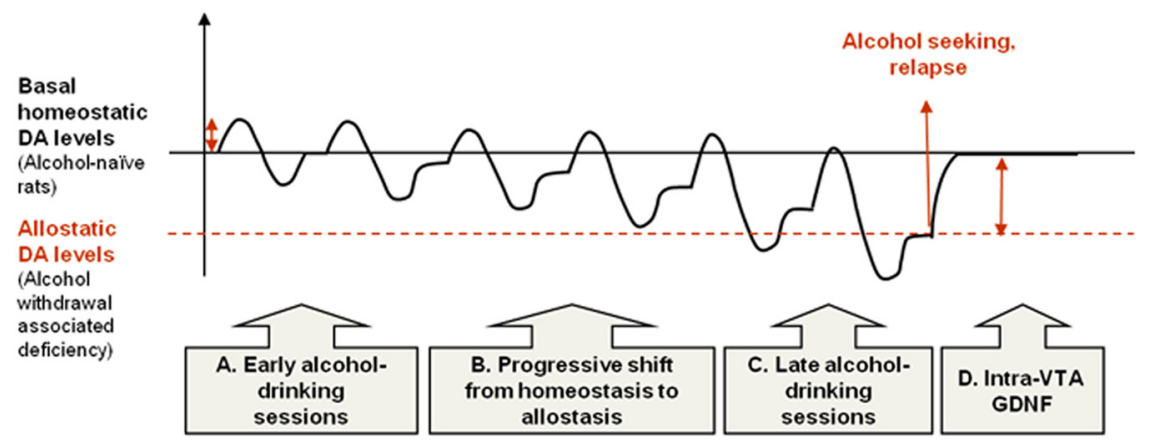

Figure 6. Diagram illustrating a model of allostatic aberration in DA levels in the NAc during prolonged excessive alcohol consumption and its reversal by GDNF. $A$, Consumption of alcohol during early drinking sessions causes an elevation in DA levels, and this is followed by a period of temporary DA deficiency during withdrawal until DA levels stabilize back to the homeostatic point. $\boldsymbol{B}$, Repeated cycles of alcohol use and withdrawal cause a progressive transition to an allostatic state in brain reward system. Thus, the basal levels of NAcDA are gradually reduced and stabilize at a lower allostatic point. C, After a prolonged period of excessive drinking and withdrawal cycles, basal NAcDA levels are lowered compared with controls. This might be associated with a negative hedonic/mood state when alcohol is absent, causing craving and alcohol seeking. Alcohol consumption can increase DA levels to levels similar to those of control rats (Weiss et al., 1996), but the levels lapse again to the allostatic levels. $D$, A single infusion of GDNF into the VTA of rats during withdrawal causes a reversal of the allostatic deviation in DA levels, as well as suppression of alcohol reward seeking, alcohol intake, and relapse (Carnicella et al., 2008, 2009a). The effects of GDNF on alcohol consumption last at least $48 \mathrm{~h}$ (Carnicella and Ron, 2009). This diagram has been adapted from a model first published in the study by Koob and Le Moal (2001).

hol (experimenter- or self-administration) are associated with a decrease in NAc DA overflow (Darden and Hunt, 1977; Gil et al., 1992; Rossetti et al., 1992; Diana et al., 1993; Weiss et al., 1996; Smith et al., 2008). In contrast, following a $24 \mathrm{~h}$ drinking session,
GDNF in the VTA is not rewarding and does not alter locomotor activity in rats The increase in DA levels in the NAc in response to drugs of abuse and alcohol has been suggested to play a role in the rewarding/reinforcing effects of the drugs (Di Chiara and Imperato, 1988; Gonzales et al., 2004; Leyton, 2007). Interestingly, although activation of the GDNF pathway in the VTA results in increased levels of DA in the NAc (Wang et al., 2010), we show that the growth factor does not induce CPP on its own, neither in alcoholnaive nor in alcohol-experienced animals, suggesting that GDNF is not rewarding. Furthermore, increases in striatal DA levels are related to the acute hyperlocomotor effects of drugs of abuse and alcohol (Wise, 1987; Kalivas and Stewart, 1991; Cohen et al., 1997; Leyton, 2007). However, we show that intra-VTA infusion of GDNF did not alter locomotor activity

(Lu et al., 2009). These data suggest that GDNF does not share the stimulant and/or rewarding properties of drugs of abuse. These differences might stem from differential kinetics in the actions of psychostimulants or alcohol versus GDNF on the mesocorticolimbic dopaminergic system. For ex- 
ample, a single GDNF infusion into the midbrain induces enhancement of the mesostriatal dopaminergic transmission in vivo, which can persist for weeks (Hudson et al., 1995; Hebert et al., 1996), and NAc extracellular DA levels remain higher than baseline for at least $3 \mathrm{~h}$ following intra-VTA GDNF infusion (Wang et al., 2010). This pattern is in contrast to the transient elevations produced by drugs of abuse and alcohol (Di Chiara and Imperato, 1988; Gonzales et al., 2004). In addition, several studies have shown that benztropine analogs, which are potent DA uptake inhibitors that produce a slow and prolonged elevation in NAc DA levels (Raje et al., 2005; Tanda et al., 2009), are associated with weak or no psychostimulant effects on locomotor activity or CPP (Desai et al., 2005; Li et al., 2005; VelázquezSánchez et al., 2009, 2010).

\section{Intra-VTA infusion of GDNF blocks acquisition and expression of alcohol place preference}

Importantly, we found that intra-VTA infusion of GDNF blocks acquisition as well as expression of alcohol-CPP in rats with a history of high levels of alcohol consumption. Although we cannot rule out the possibility that the infusion of GDNF on the last day of conditioning affects the expression of alcohol-CPP in the subsequent day, this possibility is unlikely, as the effects of GDNF are very rapid (Carnicella et al., 2008, 2009a; Wang et al., 2010).

Nevertheless, the actions of GDNF on the acquisition of alcohol place preference may reflect the inhibitory actions of GDNF on the rewarding effects of alcohol but may also result from impairment in rats' ability to learn the association between the reward and the paired chamber. Conversely, the effects of GDNF on the expression of alcohol place preference may reflect a decrease in alcohol seeking but may also result from a deficit in memory retrieval (Bardo and Bevins, 2000; Gremel and Cunningham, 2008, 2009). However, it is unlikely that activation of the GDNF pathway in the VTA causes learning and memory impairments since a global decrease in GDNF levels in GDNF heterozygote knock-out mice results in learning impairments (Gerlai et al., 2001). Moreover, we previously found that intraVTA infusion of GDNF induces an early termination of operant alcohol self-administration (Carnicella et al., 2008), also suggesting that GDNF interferes with the rewarding/reinforcing effects of alcohol, leading to a failure to maintain operant responding.

\section{Intra-VTA infusion of GDNF results in a downward shift in the dose-response curve for alcohol}

Agents that substitute for drugs of abuse (such as $\mathrm{D}_{2}$ DA receptor agonists for cocaine) shift dose-response curves to the left (Mello and Negus, 1996; Barrett et al., 2004) (Fig. 5D, model). In contrast, a downward shift is considered to reflect a decrease in the intrinsic reinforcing/rewarding properties of the self-administered drug of abuse, or a direct inhibitory effect on the motivation to selfadminister this drug (Maisonneuve and Glick, 1999; Piazza et al., 2000; Graham et al., 2007) (Fig. 5E, model). We show that intra-VTA infusion of GDNF induced a downward shift in the dose-response curve for alcohol self-administration. These findings argue against the possibility that GDNF potentiates the actions of alcohol or acts as a substitute for alcohol.

Our data suggest that withdrawal from prolonged excessive exposure to alcohol causes DA deficiency in the NAc, which is reversed by GDNF. These results fit with the possibility that alcohol seeking might be driven by a withdrawal-associated aversive state, which is alleviated by GDNF (Kenny et al., 2006; Lenoir and Keiflin, 2006). However, we previously showed that GDNF may also act on the positive reinforcing effects of alcohol. Specifically,
GDNF reverses self-administration of $10 \%$ alcohol (Carnicella et al., 2008) in rats that consume moderate levels of alcohol $(\sim 0.5$ $\mathrm{g} / \mathrm{kg}$ per $1 \mathrm{~h}$ daily session), a level of consumption that is not likely to cause withdrawal symptoms and DA deficiency (Weiss et al., 1996). Therefore, it is plausible that both positive- and negativereinforcement mechanisms mediate the capacity of GDNF to negatively regulate alcohol self-administration, by decreasing the motivation to seek and consume alcohol.

Prior work showed that the transition from moderate to excessive drug administration results in a vertical upward shift in the typical dose-response inverted U-shaped curve (Ahmed and Koob, 1998; Simms et al., 2010). This upward shift was suggested to stem from an allostatic decrease in reward function and an increase in an intrinsic "hedonic set point" (Ahmed and Koob, $1998,2005)$. Thus, the ability of GDNF to induce a vertical downward shift in the dose-response curve of alcohol intake can be taken as additional evidence for the ability of GDNF within the VTA to reverse the allostatic changes by decreasing the intrinsic hedonic set point (Fig. 6, model).

\section{Conclusions}

Our findings suggest that the activation of the GDNF pathway in the VTA reverses DA-related allostatic aberrations induced by alcohol, implying that GDNF is an "adjusting factor" of DA release after alcohol withdrawal. Thus, GDNF normalizes the pathological abnormalities in alcohol-related behavior and in the mesolimbic DA system that are induced by excessive alcohol consumption, without inducing functional abnormalities on its own. This stands in marked contrast with the available pharmacotherapies for alcohol abuse disorders, which are aimed at blocking the reinforcing effects of alcohol by inhibiting the DA mesocorticolimbic system (e.g., naltrexone), causing a nonspecific anhedonic state and discontinuation (Murphy et al., 1990; Daniel et al., 1992; Kim, 1998; Yeomans and Gray, 2002). In line with this conclusion are the observations that infusion of GDNF into the VTA has no effects on operant responding for sucrose (Carnicella et al., 2008). Similarly, we found that systemic administration of the FDA-approved drug cabergoline reduces alcohol selfadministration via the upregulation of the GDNF pathway in the VTA, but has no effect on sucrose self-administration in rats, as well as on saccharin or water intake in mice (Carnicella et al., 2009c). Together, these finding suggest that GDNF may therefore represent a novel therapeutic strategy for alcohol use and abuse disorders, which suppresses the motivation to seek and consume alcohol by reversing neurochemical and hedonic allostatic deviations induced by alcohol binge-withdrawal cycles without possessing abuse liability.

\section{References}

Ahmed SH, Koob GF (1998) Transition from moderate to excessive drug intake: change in hedonic set point. Science 282:298-300.

Ahmed SH, Koob GF (2005) Transition to drug addiction: a negative reinforcement model based on an allostatic decrease in reward function. Psychopharmacology (Berl) 180:473-490.

Airaksinen MS, Saarma M (2002) The GDNF family: signalling, biological functions and therapeutic value. Nat Rev Neurosci 3:383-394.

Bailey CP, O’Callaghan MJ, Croft AP, Manley SJ, Little HJ (2001) Alterations in mesolimbic dopamine function during the abstinence period following chronic ethanol consumption. Neuropharmacology 41:989-999.

Bardo MT, Bevins RA (2000) Conditioned place preference: what does it add to our preclinical understanding of drug reward? Psychopharmacology (Berl) 153:31-43.

Barrett AC, Miller JR, Dohrmann JM, Caine SB (2004) Effects of dopamine indirect agonists and selective $\mathrm{D}_{1}$-like and $\mathrm{D}_{2}$-like agonists and antago- 
nists on cocaine self-administration and food maintained responding in rats. Neuropharmacology 47 [Suppl 1]:256-273.

Bespalov MM, Saarma M (2007) GDNF family receptor complexes are emerging drug targets. Trends Pharmacol Sci 28:68-74.

Carnicella S, Ron D (2009) GDNF - a potential target to treat addiction. Pharmacol Ther 122:9-18.

Carnicella S, Kharazia V, Jeanblanc J, Janak PH, Ron D (2008) GDNF is a fast-acting potent inhibitor of alcohol consumption and relapse. Proc Natl Acad Sci U S A 105:8114-8119.

Carnicella S, Amamoto R, Ron D (2009a) Excessive alcohol consumption is blocked by glial cell line-derived neurotrophic factor. Alcohol 43:35-43.

Carnicella S, Ahmadiantehrani S, Janak PH, Ron D (2009b) GDNF is an endogenous negative regulator of ethanol-mediated reward and of ethanol consumption after a period of abstinence. Alcohol Clin Exp Res 33:1012-1024.

Carnicella S, Ahmadiantehrani S, He DY, Nielsen CK, Bartlett SE, Janak PH, Ron D (2009c) Cabergoline decreases alcohol drinking and seeking behaviors via glial cell line-derived neurotrophic factor. Biol Psychiatry 66:146-153.

Carnicella S, Yowell QV, Ron D (2011) Regulation of operant oral ethanol self-administration: a dose-response curve study in rats. Alcohol Clin Exp Res 35:116-125.

Cohen C, Perrault G, Sanger DJ (1997) Evidence for the involvement of dopamine receptors in ethanol-induced hyperactivity in mice. Neuropharmacology 36:1099-1108.

Cunningham CL, Gremel CM, Groblewski PA (2006) Drug-induced conditioned place preference and aversion in mice. Nat Protoc 1:1662-1670.

Daniel M, Martin AD, Carter J (1992) Opiate receptor blockade by naltrexone and mood state after acute physical activity. Br J Sports Med 26:111-115.

Darden JH, Hunt WA (1977) Reduction of striatal dopamine release during an ethanol withdrawal syndrome. J Neurochem 29:1143-1145.

Desai RI, Kopajtic TA, Koffarnus M, Newman AH, Katz JL (2005) Identification of a dopamine transporter ligand that blocks the stimulant effects of cocaine. J Neurosci 25:1889-1893.

Diana M, Pistis M, Carboni S, Gessa GL, Rossetti ZL (1993) Profound decrement of mesolimbic dopaminergic neuronal activity during ethanol withdrawal syndrome in rats: electrophysiological and biochemical evidence. Proc Natl Acad Sci U S A 90:7966-7969.

Di Chiara G, Imperato A (1988) Drugs abused by humans preferentially increase synaptic dopamine concentrations in the mesolimbic system of freely moving rats. Proc Natl Acad Sci U S A 85:5274-5278.

Gerlai R, McNamara A, Choi-Lundberg DL, Armanini M, Ross J, PowellBraxton L, Phillips HS (2001) Impaired water maze learning performance without altered dopaminergic function in mice heterozygous for the GDNF mutation. Eur J Neurosci 14:1153-1163.

Ghitza UE, Zhai H, Wu P, Airavaara M, Shaham Y, Lu L (2010) Role of $\mathrm{BDNF}$ and GDNF in drug reward and relapse: a review. Neurosci Biobehav Rev 35:157-171.

Gibb SL, Jeanblanc J, Barak S, Yowell QV, Yaka R, Ron D (2011) Lyn kinase regulates mesolimbic dopamine release: implication for alcohol reward. J Neurosci 31:2180-2187.

Gil E, Colado I, Lopez F, Fernandez-Briera A, Fernandez-Lopez A, Calvo P (1992) Effects of chronic treatment with ethanol and withdrawal of ethanol on levels of dopamine, 3,4-dihydroxyphenylacetic acid and homovanillic acid in the striatum of the rat. Influence of benzodiazepines, barbiturate and somatostatin. Neuropharmacology 31:1151-1156.

Ginsburg BC, Martinez G, Friesenhahn G, Javors M, Lamb RJ (2008) Acute tolerance to rate-decreasing effects of single doses of ethanol. Physiol Behav 94:374-383.

Gonzales RA, Job MO, Doyon WM (2004) The role of mesolimbic dopamine in the development and maintenance of ethanol reinforcement. Pharmacol Ther 103:121-146.

Graham DL, Edwards S, Bachtell RK, DiLeone RJ, Rios M, Self DW (2007) Dynamic BDNF activity in nucleus accumbens with cocaine use increases self-administration and relapse. Nat Neurosci 10:1029-1037.

Gremel CM, Cunningham CL (2008) Roles of the nucleus accumbens and amygdala in the acquisition and expression of ethanol-conditioned behavior in mice. J Neurosci 28:1076-1084.

Gremel CM, Cunningham CL (2009) Involvement of amygdala dopamine and nucleus accumbens NMDA receptors in ethanol-seeking behavior in mice. Neuropsychopharmacology 34:1443-1453.
Hebert MA, Van Horne CG, Hoffer BJ, Gerhardt GA (1996) Functional effects of GDNF in normal rat striatum: presynaptic studies using in vivo electrochemistry and microdialysis. J Pharmacol Exp Ther 279:1181-1190.

Hudson J, Granholm AC, Gerhardt GA, Henry MA, Hoffman A, Biddle P, Leela NS, Mackerlova L, Lile JD, Collins F (1995) Glial cell line-derived neurotrophic factor augments midbrain dopaminergic circuits in vivo. Brain Res Bull 36:425-432.

Hyman SE, Malenka RC, Nestler EJ (2006) Neural mechanisms of addiction: the role of reward-related learning and memory. Annu Rev Neurosci 29:565-598.

Ikemoto S (2007) Dopamine reward circuitry: two projection systems from the ventral midbrain to the nucleus accumbens-olfactory tubercle complex. Brain Res Rev 56:27-78.

Kalivas PW, Stewart J (1991) Dopamine transmission in the initiation and expression of drug- and stress-induced sensitization of motor activity. Brain Res Brain Res Rev 16:223-244.

Kenny PJ, Chen SA, Kitamura O, Markou A, Koob GF (2006) Conditioned withdrawal drives heroin consumption and decreases reward sensitivity. J Neurosci 26:5894-5900.

Keppel G (1991) Design and analysis: a researcher's handbook, Ed 3. Upper Saddle River, NJ: Prentice Hall.

Kim SW (1998) Opioid antagonists in the treatment of impulse-control disorders. J Clin Psychiatry 59:159-164.

Koob GF (1996) Drug addiction: the yin and yang of hedonic homeostasis. Neuron 16:893-896.

Koob GF (2003) Alcoholism: allostasis and beyond. Alcohol Clin Exp Res 27:232-243.

Koob GF, Le Moal M (1997) Drug abuse: hedonic homeostatic dysregulation. Science 278:52-58.

Koob GF, Le Moal M (2001) Drug addiction, dysregulation of reward, and allostasis. Neuropsychopharmacology 24:97-129.

Lenoir M, Keiflin R (2006) Heroin addiction: anticipating the reward of heroin or the agony of withdrawal? J Neurosci 26:9080-9081.

Lewis MJ, June HL (1990) Neurobehavioral studies of ethanol reward and activation. Alcohol 7:213-219.

Leyton M (2007) Conditioned and sensitized responses to stimulant drugs in humans. Prog Neuropsychopharmacol Biol Psychiatry 31:1601-1613.

Li SM, Newman AH, Katz JL (2005) Place conditioning and locomotor effects of $N$-substituted, $4^{\prime}, 4^{\prime \prime}$-difluorobenztropine analogs in rats. J Pharmacol Exp Ther 313:1223-1230.

Lin LF, Doherty DH, Lile JD, Bektesh S, Collins F (1993) GDNF: a glial cell line-derived neurotrophic factor for midbrain dopaminergic neurons. Science 260:1130-1132.

Lu L, Wang X, Wu P, Xu C, Zhao M, Morales M, Harvey BK, Hoffer BJ, Shaham Y (2009) Role of ventral tegmental area glial cell line-derived neurotrophic factor in incubation of cocaine craving. Biol Psychiatry 66:137-145

Lynch WJ, Carroll ME (2001) Regulation of drug intake. Exp Clin Psychopharmacol 9:131-143.

Maisonneuve IM, Glick SD (1999) Attenuation of the reinforcing efficacy of morphine by 18-methoxycoronaridine. Eur J Pharmacol 383:15-21.

McBride WJ, Murphy JM, Ikemoto S (1999) Localization of brain reinforcement mechanisms: intracranial self-administration and intracranial placeconditioning studies. Behav Brain Res 101:129-152.

Mello NK, Negus SS (1996) Preclinical evaluation of pharmacotherapies for treatment of cocaine and opioid abuse using drug self-administration procedures. Neuropsychopharmacology 14:375-424.

Meyer PJ, Meshul CK, Phillips TJ (2009) Ethanol- and cocaine-induced locomotion are genetically related to increases in accumbal dopamine. Genes Brain Behav 8:346-355.

Murphy MR, Checkley SA, Seckl JR, Lightman SL (1990) Naloxone inhibits oxytocin release at orgasm in man. J Clin Endocrinol Metab 71:1056-1058.

Nurmi M, Kiianmaa K, Sinclair JD (1994) Brain ethanol in AA, ANA, and Wistar rats monitored with one-minute microdialysis. Alcohol 11:315-321.

Pascual A, Hidalgo-Figueroa M, Piruat JI, Pintado CO, Gómez-Díaz R, López-Barneo J (2008) Absolute requirement of GDNF for adult catecholaminergic neuron survival. Nat Neurosci 11:755-761.

Paxinos G, Watson C (1998) The rat brain in stereotaxic coordinates, Ed 4. San Diego: Academic.

Piazza PV, Deroche-Gamonent V, Rouge-Pont F, Le Moal M (2000) Vertical 
shifts in self-administration dose-response functions predict a drugvulnerable phenotype predisposed to addiction. J Neurosci 20:4226-4232.

Pierce RC, Kumaresan V (2006) The mesolimbic dopamine system: the final common pathway for the reinforcing effect of drugs of abuse? Neurosci Biobehav Rev 30:215-238.

Raje S, Cornish J, Newman AH, Cao J, Katz JL, Eddington ND (2005) Pharmacodynamic assessment of the benztropine analogues AHN-1055 and AHN-2005 using intracerebral microdialysis to evaluate brain dopamine levels and pharmacokinetic/pharmacodynamic modeling. Pharm Res 22:603-612.

Rossetti ZL, Melis F, Carboni S, Diana M, Gessa GL (1992) Alcohol withdrawal in rats is associated with a marked fall in extraneuronal dopamine. Alcohol Clin Exp Res 16:529-532.

Shen RY (2003) Ethanol withdrawal reduces the number of spontaneously active ventral tegmental area dopamine neurons in conscious animals. J Pharmacol Exp Ther 307:566-572.

Shen RY, Choong KC, Thompson AC (2007) Long-term reduction in ventral tegmental area dopamine neuron population activity following repeated stimulant or ethanol treatment. Biol Psychiatry 61:93-100.

Simms JA, Steensland P, Medina B, Abernathy KE, Chandler LJ, Wise R, Bartlett SE (2008) Intermittent access to $20 \%$ ethanol induces high ethanol consumption in Long-Evans and Wistar rats. Alcohol Clin Exp Res 32:1816-1823.

Simms JA, Bito-Onon JJ, Chatterjee S, Bartlett SE (2010) Long-Evans rats acquire operant self-administration of $20 \%$ ethanol without sucrose fading. Neuropsychopharmacology 35:1453-1463.

Smith JE, Co C, McIntosh S, Cunningham CC (2008) Chronic binge-like moderate ethanol drinking in rats results in widespread decreases in brain serotonin, dopamine, and norepinephrine turnover rates reversed by ethanol intake. J Neurochem 105:2134-2155.

Tanda G, Newman AH, Ebbs AL, Tronci V, Green JL, Tallarida RJ, Katz JL
(2009) Combinations of cocaine with other dopamine uptake inhibitors: assessment of additivity. J Pharmacol Exp Ther 330:802-809.

Tzschentke TM (2007) Measuring reward with the conditioned place preference (CPP) paradigm: update of the last decade. Addict Biol 12:227-462.

Velázquez-Sánchez C, Ferragud A, Hernández-Rabaza V, Nácher A, Merino V, Cardá M, Murga J, Canales JJ (2009) The dopamine uptake inhibitor 3 alpha-[bis( $4^{\prime}$-fluorophenyl)metoxy]-tropane reduces cocaine-induced early-gene expression, locomotor activity, and conditioned reward. Neuropsychopharmacology 34:2497-2507.

Velázquez-Sánchez C, Ferragud A, Murga J, Cardá M, Canales JJ (2010) The high affinity dopamine uptake inhibitor, JHW 007, blocks cocaineinduced reward, locomotor stimulation and sensitization. Eur Neuropsychopharmacol 20:501-508.

Wang J, Carnicella S, Ahmadiantehrani S, He DY, Barak S, Kharazia V, Ben Hamida S, Zapata A, Shippenberg TS, Ron D (2010) Nucleus accumbensderived glial cell line-derived neurotrophic factor is a retrograde enhancer of dopaminergic tone in the mesocorticolimbic system. J Neurosci 30:14502-14512.

Weiss F, Parsons LH, Schulteis G, Hyytiä P, Lorang MT, Bloom FE, Koob GF (1996) Ethanol self-administration restores withdrawal-associated deficiencies in accumbal dopamine and 5-hydroxytryptamine release in dependent rats. J Neurosci 16:3474-3485.

Wise RA (1973) Voluntary ethanol intake in rats following exposure to ethanol on various schedules. Psychopharmacologia 29:203-210.

Wise RA (1987) The role of reward pathways in the development of drug dependence. Pharmacol Ther 35:227-263.

Yeomans MR, Gray RW (2002) Opioid peptides and the control of human ingestive behaviour. Neurosci Biobehav Rev 26:713-728.

Zapata A, Shippenberg TS (2005) Lack of functional $\mathrm{D}_{2}$ receptors prevents the effects of the $\mathrm{D}_{3}$-preferring agonist (+)-PD 128907 on dialysate dopamine levels. Neuropharmacology 48:43-50. 